Dept. of Pathology,

Faculty of Vet. Med., Assiut Univ.,

Head of Dept. Prof. Dr. M.l. El-Sherry.

\title{
EPIDEMIOLOGICAL AND PATHOLOGICAL STUDIES ON ADENOVIRUS INFECTION IN BROILER CHICKENS
}

(With 1 Table \& 9 Figs.)

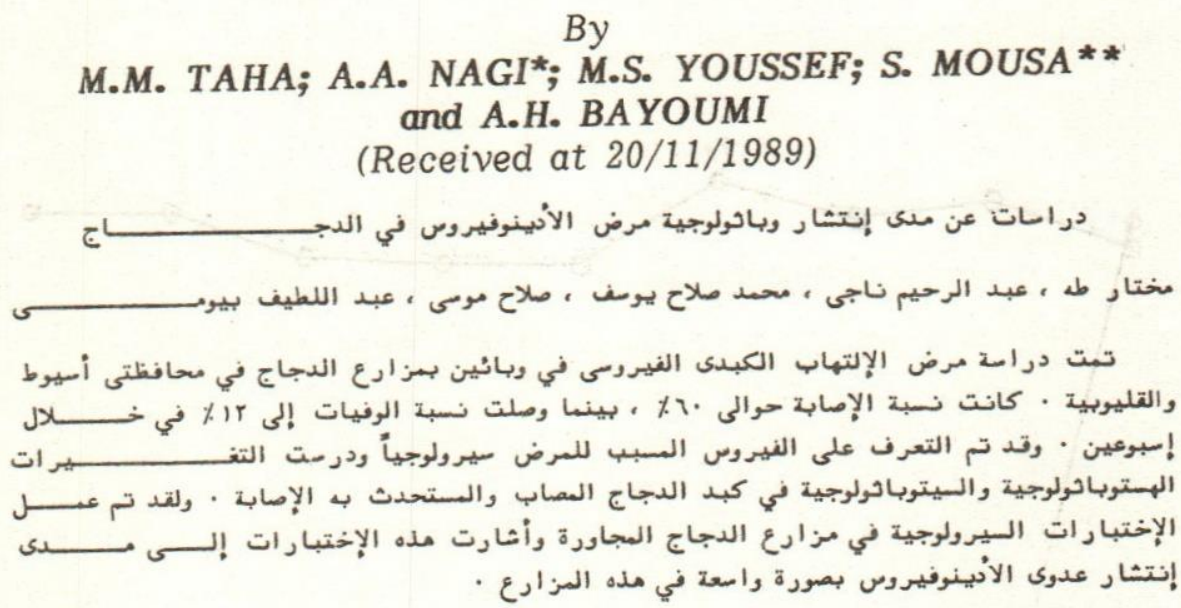

\section{SUMMARY}

Two outbreaks of inclusion body hepatitis (IBH) were observed in broiler poultry farms at Assiut and Ei-Kalubia governorates. Morbidity rate was about $60 \%$, while the commulative mortalities reached $12 \%$ during a course of two weeks. The post-mortem findings, and the hepatic histomorphological and cytopathological alterations were described and illustrated. The causative virus was serologically identified. Moreover, the disease was successfully reproduced in susceptible chickens. Serological survey in the neighbouring farms revealed the wide spread of adenovirus infection.

\section{INTRODUCTION}

Several different viruses cause hepatitis in birds (FABRICANT, et al. 1957; CORNWELL and WRIGHT, 1970 and RIDDELL, 1984).

Adenoviruses have a widespread occurrence in many avian species. Since, 1954, numerous viruses having the biologic, physical and chemical characteristics of the

* Dept. of Pathology, Faculty of Vet. Med., Moshtohour, Zagazig Univ.

** Dept. of Poultry Dis., Faculty of Vet. Med., Assiut Univ.

Assiut Vet.Med.l. Vol. 23, No. 45, April 1990. 


\section{M.M. TAHA, et al.}

genus Aviadenovirus were isolated from chickens and chicken embryos (FENNER, et al. 1974). The most well known adenovirus infection in broiler chickens is the inclusion body hepatitis (IBH) (HELMBOLDT and FRAZIER, 1965). It is generally agreed that this condition is due to adenovirus infecting an immunodepressed bird (FADLY and WINTERFIELD, 1973). Disruption of hepatic architecture, focal necrosis and presence of intranuclear inclusions are the most pathogenomic lesions of the disease (GRIMES, et al. 1978).

Agar gel precipitin (AGP) test is helpfull in determining the exposure to an adenovirus since it detects both type-and group-antigens (MCFERRAN, et al. 1976).

This investigation dealt with two outbreaks of $\mathbb{B H}$ in broiler chickens. The aims of this study were isolation and identification of the causal agent,description of the hepatopathic alterations, and determination of the epidemiology of the disease in Assiut as well as El-Kalubia governorate. An evaluation of the tissue imprinting technique as a rapid test for diagnosis of such diseases was also given.

\section{MATERIAL and METHODS}

The present study dealt with two outbreaks occurred simultaneously in two flocks of 30,000 and 60,000 Arbor Acer chicks aged 30 to 45 days at Assiut and El-Kalubia governorates. The morbidity rate reached about $60 \%$, while the commulative mortality ranged from 10 to $14 \%$ in two weeks.

A total of 100 dead and moribund birds were subjected to post-mortem, virological, histopathological and cytological examinations.

\section{Virus isolation:}

Liver specimens were processed for egg inoculation on the chorioallantoic membrane (CAM) of 11-day-old chick embryos. The infected CAMs were collected and stored at $-20^{\circ} \mathrm{C}$ till used for $A G P$ test.

\section{Reference viruses and antisera:}

Adenovirus serotypes and antisera were kindly supplied by the Dept. of Poultry Diseases, Assiut University. Phelps, Indiana C and Tipton serotypes and homologous antisera were used.

\section{Serum samples:}

Fifty serum samples were collected from each of 10 farms in Assiut and ElKalubia governorates. The samples were obtained from broiler and layer flocks of different ages. They were subjected to AGP test against antigen of Phelps strain.

\section{Agar-gel precipitin test:}

The microtechnique was carried out according to BOYLE (1973).

Assiut Vet.Med.J. Vol. 23, No. 45, April 1990. 


\section{BH INFECTION IN CHICKENS}

\section{Reproduction of the disease:}

A total of 30 Lohman broiler chicks of 28-day-old were obtained from Kena poultry farm. Serum samples proved to be free from precipitating antibodies against Phelps strain. The birds were divided into 3 equal groups. Chicks, of the first two groups were intraperitoneally inoculated at age of 5 weeks with $10^{4}$ embryo infective dose $50\left(E_{50}\right)$ of either the Assiut or El-Kalubia isolates. The third group served as non-infected control. All the 3 groups were separately reared, clinically observed, and 5 chicks from each group were sacrificed on the 5 th and 10th day post-inoculation. Liver specimens were obtained for histopathological and cytological examinations. Virus reisolation from pooled samples was also done.

\section{Histopathology:}

After careful post-mortem examination of both the naturally and experimentally infected birds, tissue specimens from the liver were taken and fixed in 10\% neutral buffered formalin. Paraffin sections were prepared, stained with haematoxylin and eosin ( $H$ \& $E)$ stain and examined.

\section{Cytology:}

Very small tissue masses were obtained from the liver. The removed masses were firstly cut in half to obtain a freshly cut surface. The cut surface was blooted repeatedly upon a clean paper towel until it became as dry and as free from blood as possible. The dry cut surface was touched gently to a clean glass slide, and several rows of the imprints were made on each slide. The imprinted slides were fixed in ether: ethanol $1: 1$, and stained with Giemsa and $H$ \& $E$ stains.

\section{RESULTS}

\section{Virus isolation:}

Liver suspensions caused no deaths of the inoculated embryos, but on the 3 rd passage pock lesions were observed on the CAMs. In AGP test, they reacted positively against Phelps and Tipton antisera, and gave negative results against Indiana $\mathrm{C}$ antiserum.

\section{Serological findings:}

The obtained results were tabulated in the following table: 
M.M. TAHA, et al.

Results of AGP test of serum sampies

\begin{tabular}{rrrrrr}
\hline \multirow{2}{*}{ Flock } & \multirow{2}{*}{$\begin{array}{c}\text { Age in } \\
\text { weeks }\end{array}$} & Breed & No. of & \multicolumn{2}{c}{ AGP test } \\
\cline { 5 - 6 } & & & samples & Positive & Percent \\
\hline 1 & 6 & Lohman & 50 & 5 & $10 \%$ \\
2 & 7 & Arbor Acer & 50 & 0 & $0 \%$ \\
3 & 7 & Hubbard & 50 & 6 & $12 \%$ \\
4 & 20 & LSL & 50 & 6 & $12 \%$ \\
5 & 50 & LSL & 50 & 14 & $28 \%$ \\
6 & 7 & Hubbard & 50 & 9 & $18 \%$ \\
7 & 30 & LSL & 50 & 3 & $6 \%$ \\
8 & 50 & LSL & 50 & 12 & $24 \%$ \\
9 & 7 & Arbor Acer & 50 & 16 & $32 \%$ \\
10 & 7 & Lohman & 50 & 0 & $0 \%$ \\
\hline
\end{tabular}

\section{Post-mortem findings:}

On necropsy, the liver of naturally infected chickens was swollen and revealed subcapsular peticheal, ecchymotic or even brush paint-like haemorhages. In addition, greyish-white foci alternated with patchy areas of discolouration were obvious in all the examined cases. These foci were surrounded by well-defined congested zones. Regarding the experimentally infected birds, more advanced areas of necrosis and haemorhages were recognized in the liver.

\section{Histopathological findings:}

The histomorphological appearance of the hepatic lesions observed in the naturally infected cases didn't vary significantly from their experimentally-induced counterparts. The liver showed wide areas of hepatocellular degeneration expressed by cytoplasmic vacuolation with subsequent disruption of some hepatic cords. However in some cases, such hepatopathic alterations were progressive and diffuse.

Besides, focal areas of coagulation necrosis were a constant finding in the liver of nearly all the examined birds. These necrotic foci showed an increased acidophilia of the cytoplasm, together with pyknosis, karyorhexis or even karyolysis of the nuclei. In some cases, the necrotic foci were characterized by advanced lytic changes of the hepatocytes (Fig. 1). Such necrotic foci were surrounded by an inflammatory celluiar reaction of mononuclear cells which supervened to lymphocytic granulomatous reaction in some of the affected cases (Fig. 2).

In addition, characteristic large intranuclear acidophilic and/or basophilic inclusion bodies surrounded by clear halo zones could be also recognized in the less severaly

Assiut Vet.Med.J. Vol. 23, No. 45, April 1990. 


\section{BH INFECTION IN CHICKENS}

affected hepatocytes (Fig. 3). Congestion of the hepatic vasculature and multiple focal haemorrhages were evident in all the examined birds (Fig. 4).

\section{Cytopathological findings:}

The liver imprints of both naturally and experimentally infected birds visualized the hepatocellular alterations of adenovirus infection. Cellular degenerative changes were manifested by hepatocellular swelling and cytoplasmic vacuolation (Fig. 5). Moreover, the morphological criteria of hepatic necrosis were expressed by a quite prominent fragmentation of the nuclear chromatin (Fig. 6) or its dissolution or condensation on the nuclear membrane (Fig. 7). In some cases, focal lymphocytic aggregations could be seen (Fig. 8). The majority of the examined imprints also revealed the intranuclear inclusions characteristic for $\mathrm{IBH}$-infection (Fig. 9).

\section{Virus reisolation:}

The virus could be reisolated from the experimentally infected birds, and produced similar lesions on CAM which reacted positively in AGP test against Phelps and Tipton
antisera.

\section{DISCUSSION}

As shown in the present study, the results of AGP test revealed that the serum samples which were collected from different sources and ages of chickens possessed precipitating antibodies against adenoviruses. These serological findings indicated the
wide spreading of adenovirus infections.

In spite of the high morbidity and mortality rates (60\% and $12 \%$ respectively), no significant clinical signs could bo recognized. This was in accordance with WELLS, et al. (1977) who reported similar mortalities, and HOFSTAD (1984) who stated that the adenovirus infections are most probably silent.

Inoculation of the chicken embryos with the isolated virus caused no deaths until the third passage which revealed pock lesions on the CAM. Similar results were also reported by MCFERRAN, et al, (1976). The isolates showed clear precipitation against Phelps and Tipton antisera, and negatively reacted against Indiana C antiserum. This refers to the sharing antigen with these serotypes (ROSENBERGER, et al. 1974).

The post-mortem findings observed in this work were quite similar to those described by GRIMES, et al. (1978) who considered them to be pathognomic for inclusion body hepatitis in broiler chickens. Furthermore, the histopathological alterations observed in the natural and experimental adenovirus infections were oftenly the same. They were expressed by hepatocytic vacuolation, focal areas of coagulation necrosis and blood extravasation, and the intranuclear inclusion bodies.Similar findings were described by GALLINA, et al. (1973), GRIME.S, et al. (1978) and LEE, et al. (1978) in adenovirus infection and experimental inclusion body hepatitis in chickens.

Assiut Vet_Med.J. Vol. 23, No. 45, April 1990. 
M.M. TAHA, et al.

The presence of the intranuclear inclusion bodies was most striking. Both the acidophilic and basophilic types were observed in the two outbreaks of the disease, and they may represent the different phases of virus replication in the nuclei of hepatocytes. On reviewing the current literature, a debate about the nature of these inclusions was found. FADLY and WINTERFIELD (1973) detected the basophilic inclusions in the natural and experimental adenoviruses infections, and they suggested that their presence depends upon the stage of infection and severity of lesions. Futher, ITAKURA, et al. (1977) observed numerous viruses in the basophilic inclusions when examined with the electron microscope. The latter authors also found that the eosinophilic inclusions contained only fibrillar granular material and filaments. Moreover, EL-SHEIKHLY and MUTALIB (1979) provided an additional evidence when they isolated the virus from the liver that had the basophilic inclusions. On the other hand, RIDDELL (1987) stated that the eosinophilic inclusions may represent a degenerative process, an early stage in formation of virus, or a late stage after the virus has left the nucleus.

In this investigation, the liver imprints revealed cytopathic alterations in the hepatocytes. Both the cytoplasmic and nuclear degenerative changes were more prominent and easily detectable. These changes together with the more pronounced lymphocytic aggregations and the pathognomic intranuclear inclusions may refer to the imprinting technique as a convenient and valuable field test for rapid diagnosis of inclusion body hepatitis in broiler chickens. It is advisable for the clinician to follow up such technique as an aid for diagnosis.

\section{REFERENCES}

Boyle, DB. (1973): Precipitating antibodies for an avian adenovirus in queensland. Aust. Vet. J., 49: 463-465.

Cornwell, H.J.C. and Wright, N.G. (1970): Herpesvirus infection of pigeons. I- Pathology and virus isolation. J. Comp. Pathol., 80: 221-227.

El-Sheikhly, F. and Mutalib, A.A. (1979): Inclusion body hepatitis in broiler chickens in Iraq. Avian Dis., 23: 763-767.

Fabricant, J.; Rickard, C.G. and Levine, P.P. (1957): The pathology of duck virus hepatitis. Avian Dis., 1: 256-275.

Fadly, A.M. and Winterfield, R.W. (1975): Isolation and some characteristics of an agent associated with inclusion body hepatitis, haemorrhagic and aplastic anaemia in chickens. Avian Dis., 17: 182-193.

Fenner, F.; McAsulan, B.R.; Mims, C.A.; Sambrook, J. and White, D.O. (1974): The biology of animal viruses. 2nd ed., Academic press, New York.

Gallina, A.M.; Winterfield, R.W. and Fadly, A.M. (1973): Adenovirus infection and disease. II- - Histopathology of naturai and experimental disease. Avian Dis., 17: 343-353.

Grimes, T.M.; Fletcher, O.J. and Munnell, J.F. (1978): Comparative study of experimental inclusion body hepatitis of chickens caused by two serotypes of avian adenovirus. Vet. Pathol., 15: 249-263.

Assiut Vet.Med.J. Vol. 23, No. 45, April 1990. 


\section{BH INTECTION IN CHICKENS}

Helmboldt, C.F. and Frazier, M.N. (1963): Avian hepatic inclusion bodies of unknown significance. Avian Dis., 7: 446-450.

Hofstad, M. (1984): Diseases of poultry. 8th ed., lowa state University press, Ames lowa, USA.

itakura, C.; Matsushita, S. and Goto, M. (1977): Fine structure of inclusion bodies in hepatic cells of chickens naturaliy affected with inclusion body hepatitis. Avian Pathol., 6: 19-32.

Lee, K.P.; Henry, N.W. and Rosenberger, J.K. (1978): Comparative pathogenicity of six adenovirus isolants in the liver. Avian Dis., 22: 610-619.

McFerran, J.B.; McCracken, R.M.; Conner, T.J. and Evans, R.T. (1976): Isolation of viruses from clinical outbreaks of inclusion body hepatitis. Avian Pathol., 5: 315-324.

Riddell, C. (1984): Viral hepatitis in domestic geese in Saskatchewan. Avian Dis., 28: 774-782.

Riddeil, C. (1987): Avian Histcpathology, American Association of Avian Pathologists. Allen press, Kanisas, USA.

Rosenberger, J.K.; Eckroade, R.J.; Klopp, S. and Krauss, W.C. (1974): Characterization of several viruses isolated from chickens with inclusion body hepatitis and aplastic anaemia. Avian Dis., 18: 399-409.

Wells, R.J.H.; Westbury, H.A.; Harrigan, K.E.; Coleman, G.D.C. and Beilharz, R.G. (1977): Epidemic adenovirus inclusion body of the chicken in Australia. Aust. Vet. J., 53: 586-590.

\section{DESCRIPTION OF FIGURES}

Fig. (1): Liver showing features of ccagulative necrosis and lytic changes of some necrosed hepatocytes. H \& E stain, X 250.

Fig. (2): Liver showing focal lymphocytic aggregation. H \& E stain, X 250.

Fig. (3): Liver showing intranuclear inclusion body in a hepatocyte. H \& $E$ stain, $X 1000$.

Fig. (4): Liver showing focal area of haemorrhage. $H \& E$ stain, $X 250$.

Fig. (5): Liver imprint showing hepatocellular swelling and cytoplasmic vacuolation. $H$ \& E stain, $X 1000$.

Fig. (6): Liver imprint showing hepatocytic nuclear fragmentation H\&E stain, $X 1000$.

Fig. (7): Liver imprint showing dissolution of hepatocytic nuclear chromatin. $H$ \& E stain, $\times 1000$. $\begin{aligned} \text { Fig.(8): } & \text { Liver irnprint showing focal lymphocytic granulomatous reaction. } H \text { \& } E \text { stain, } \\ & \times 1000 .\end{aligned}$

Fig. (9): Liver imprint showing intranuclear inclusion body in a hepatocyte (arrow). $H \& E$ stain, $X 1000$.

Assiut Vet.Med.J. Vol. 23, No. 45, April 1990. 


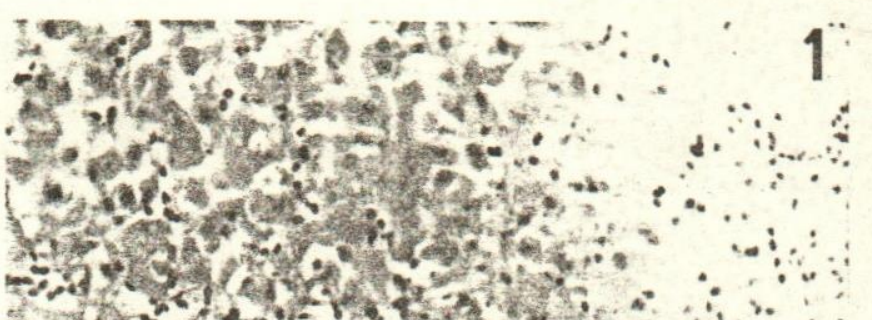

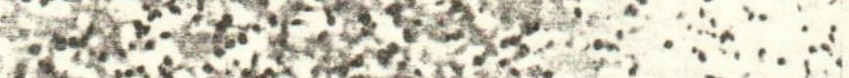
(T) of. ${ }^{2}$.

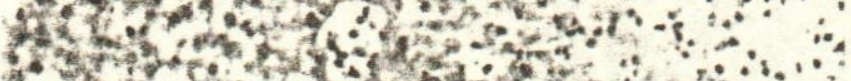

3.

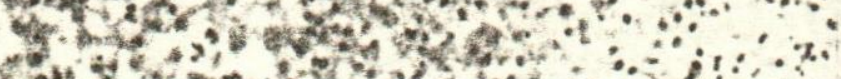

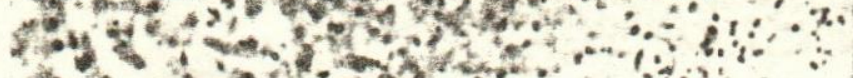

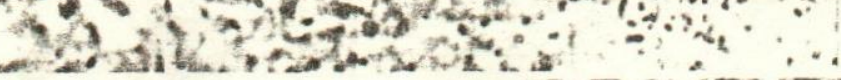

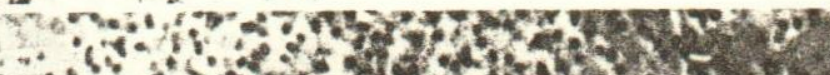

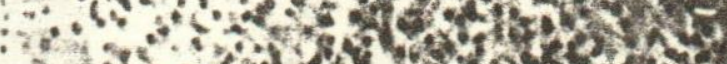

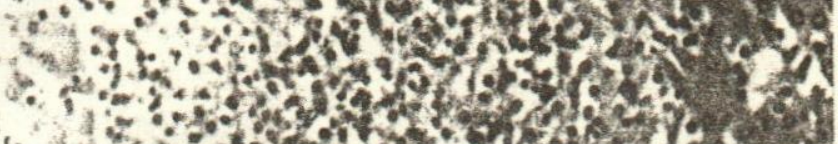

in

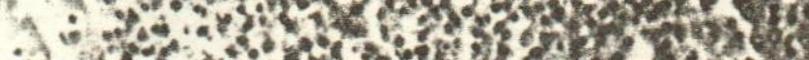

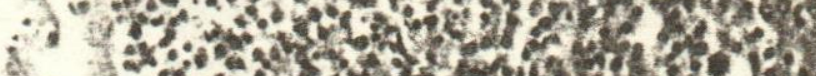

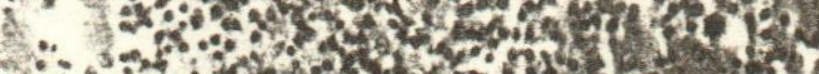

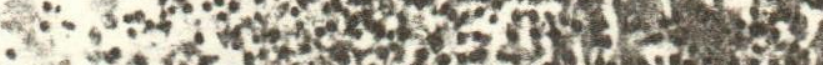

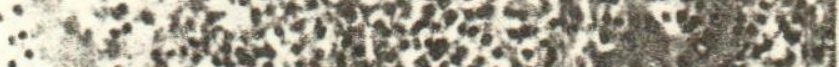

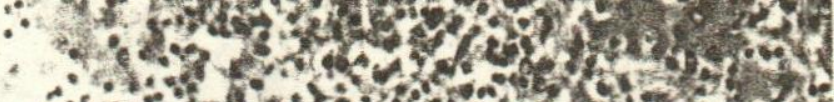

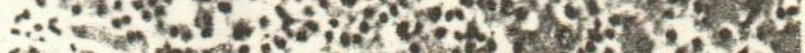

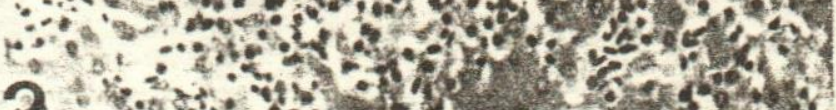

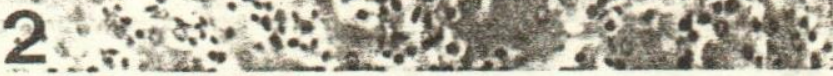

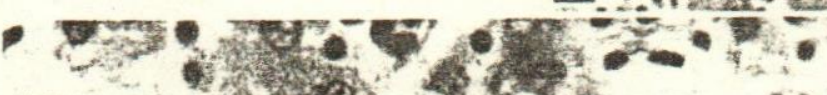
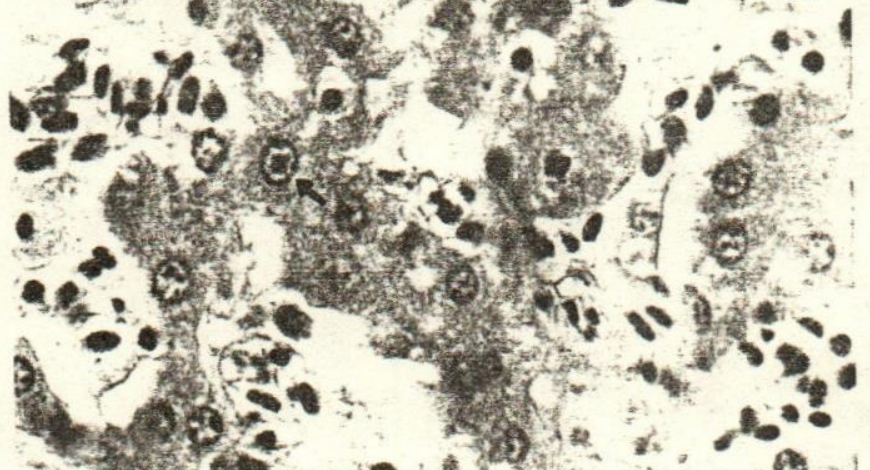

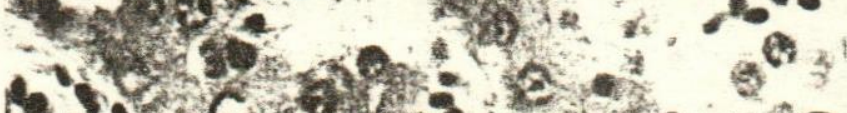

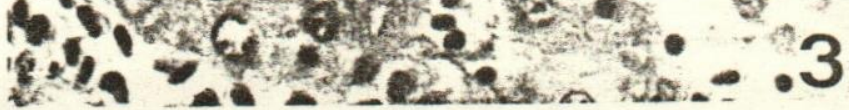




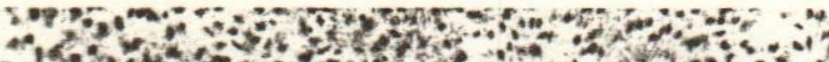

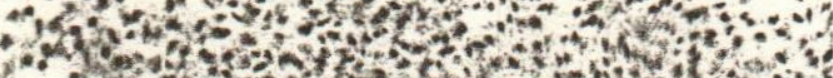

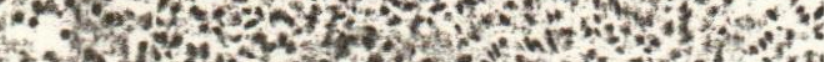

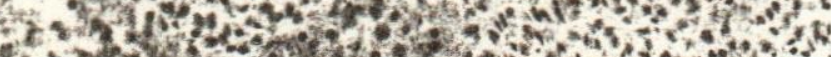
Pf : B.

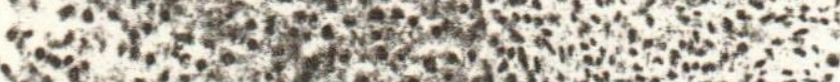

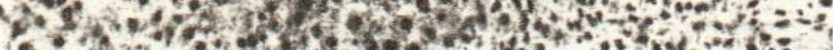

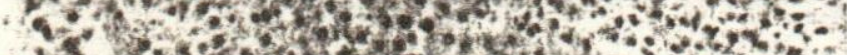

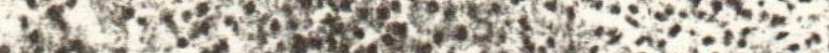

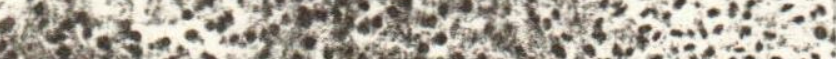

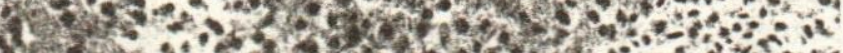

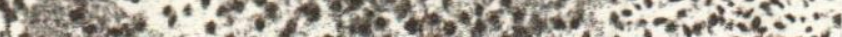

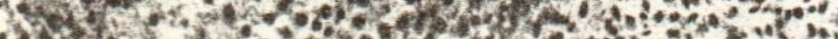

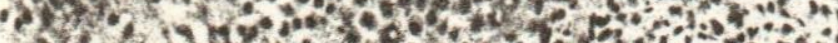

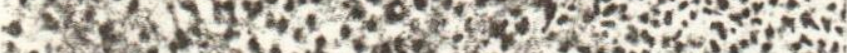

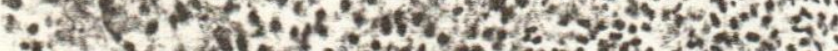

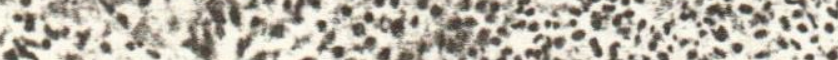

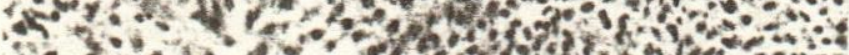

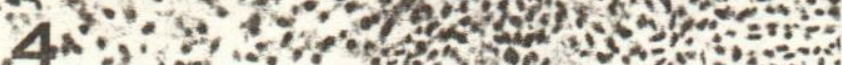

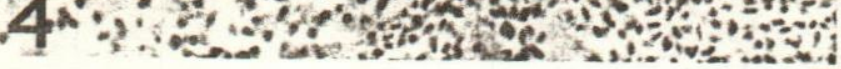

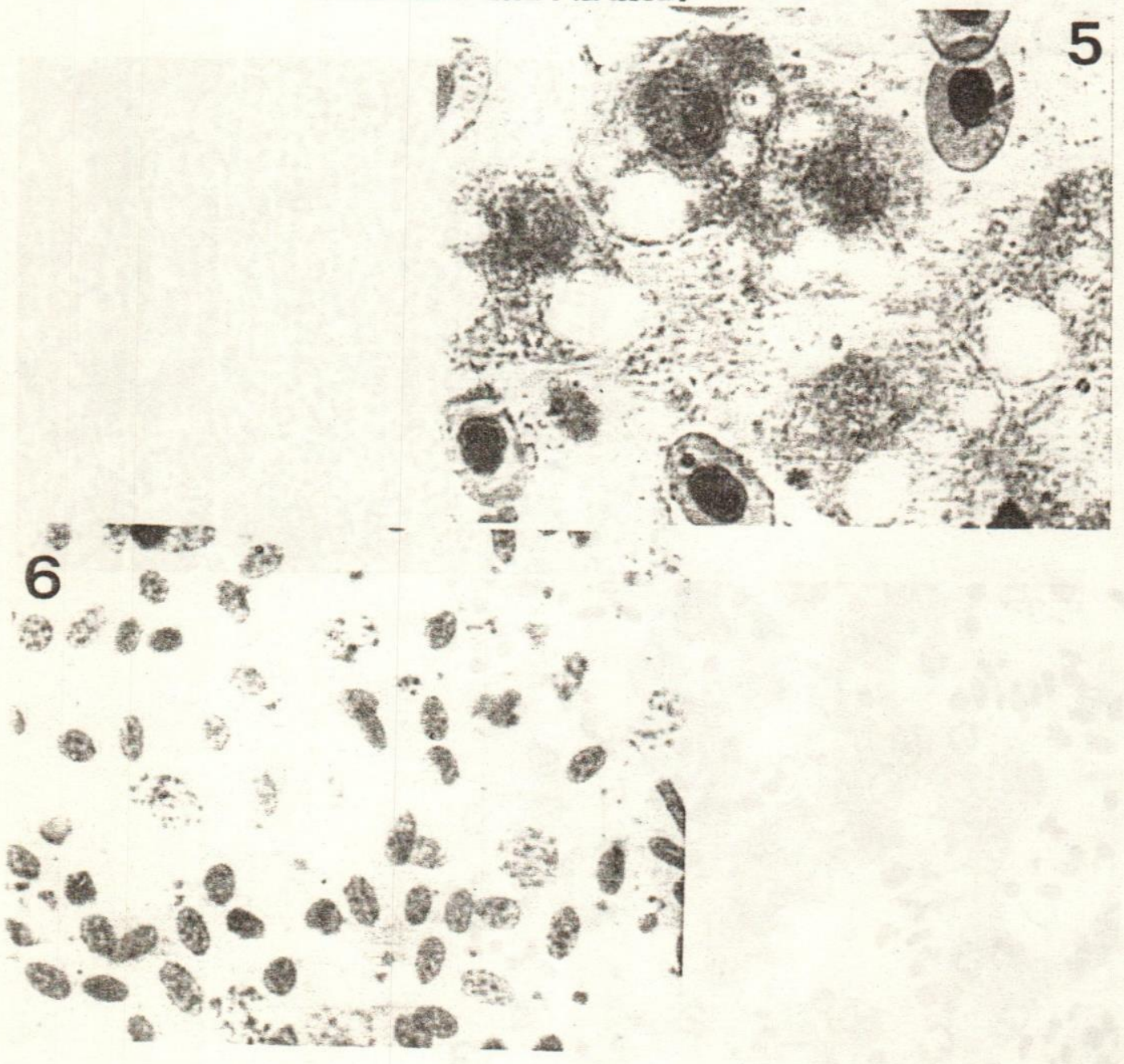



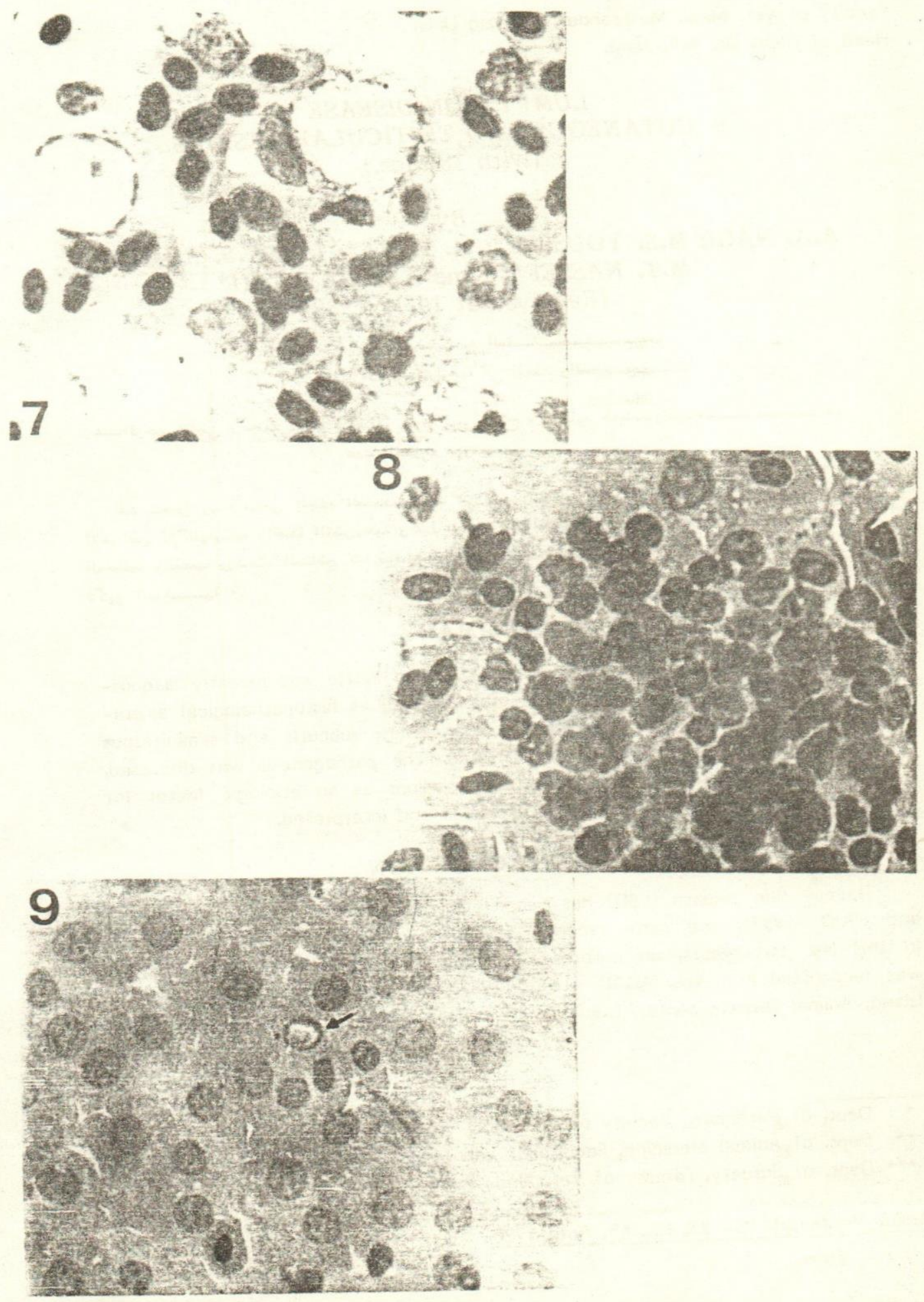